RESEARCH ARTICLE

\title{
Zoledronic Acid Inhibits the RhoA-mediated Amoeboid Motility of Pros- tate Cancer Cells
}

\author{
Laura Pietrovito ${ }^{1, \#}$, Giuseppina Comito ${ }^{1, \#}$, Matteo Parri ${ }^{1}$, Elisa Giannoni ${ }^{1}$, Paola Chiarugi ${ }^{1, \#}$ and \\ Maria Letizia Taddei ${ }^{1,2,3, *}$
}

${ }^{I}$ Dipartimento di Scienze Biomediche Sperimentali e Cliniche, Università degli Studi di Firenze, Viale Morgagni 50, 50142 Firenze; ${ }^{2}$ Dipartimento di Medicina Sperimentale e Clinica, Università degli Studi di Firenze, Viale Morgagni 50, 50142 Firenze; ${ }^{3}$ Tuscany Tumor Institute and "Center for Research, Transfer and High Education DenoTHE", 50134 Florence, Italy

A R T I C L E H I S T O R Y
Received: September 11, 2018
Revised: November 22, 2018
Accepted: January 04, 2019
DOI:
10.2174/1568009619666190115142858

$10.2174 / 1568009619666190115142858$

\begin{abstract}
Background: The bisphosphonate Zoledronic acid (ZA) is a potent osteoclast inhibitor currently used in the clinic to reduce osteoporosis and cancer-induced osteolysis. Moreover, ZA exerts an anti-tumor effect in several tumors. Despite this evidence, the relevance of ZA in prostate cancer $(\mathrm{PCa})$ is not completely understood.

Objective: To investigate the effect of ZA administration on the invasive properties of PC3 cells, which are characterised by RhoA-dependent amoeboid motility.

Methods: The effect of ZA administration on the in vitro invasive properties of PC3 cells was evaluated by cell migration in 3D collagen matrices, immunofluorescence and Boyden assays or transendothelial migration. Lung retention and colonization assays were performed to assess the efficacy of ZA administration in vivo.

Results: PC3 cells are characterised by RhoA-dependent amoeboid motility. We now report a clear inhibition of in vitro PC3 cell invasion and RhoA activity upon ZA treatment. Moreover, to confirm a specific role of ZA in the inhibition of amoeboid motility of PC3 cells, we demonstrate that ZA interferes only partially with PC3 cells showing a mesenchymal phenotype due to both treatment with conditioned medium of cancer associated fibroblasts or to the acquisition of chemoresistance. Furthermore, we demonstrate that ZA impairs adhesion to endothelial cells and the trans-endothelial cell migration, two essential properties characterising amoeboid motility and PC3 metastatic dissemination. In vivo experiments prove the ability of ZA to inhibit the metastatic process of PC3 cells as shown by the decrease in lung colonization.
\end{abstract}

Conclusion: This study demonstrates that ZA inhibits Rho-dependent amoeboid motility of PC3 cells, thus suggesting ZA as a potential therapy to impede the metastatic dissemination of PC3 cells.

Keywords: Prostate cancer, zoledronic acid, amoeboid motility, RhoA, metastasis, endothelium.

\section{INTRODUCTION}

Zoledronic acid (ZA) is an aminobisphosphonate proven to be useful in the clinic for the treatment of bone metastasis in breast, prostate, lung cancer and melanomas [1-4]. Indeed, many cancers are osteotropic and bone is the most common site of metastasis. Indeed the majority of cancer patients develop skeletal lesions during disease progression. Patients with bone metastases have an increased risk of developing fractures due to the enhancement of the osteoclastic action, bone pain, decreased haematopoiesis hence resulting in anaemia as well as hypercalcemia [5]. Skeletal-related events (SREs) are a common impediment of bone metastases and bisphosphonates are effective in preventing/delaying SREs,

*Address correspondence to this author at the Department of Experimental and Clinical Medicine, University of Florence, Viale Morgagni 50, 50134 Firenze, Italy; Tel: -39-055-2751246; E-mail: marialetizia.taddei@unifi.it

${ }^{\#}$ These authors have contributed equally to this work preserving the patients' quality of life. Actually, bisphosphonates decrease the rate of bone resorption by promoting apoptosis of osteoclasts [6]. Therefore, they are the most commonly recommended drugs to treat several pathologies such as osteoporosis, but also for Paget's disease of bone, bone metastasis, multiple myeloma, primary hyperparathyroidism, osteogenesis imperfecta, fibrous dysplasia, and other conditions that exhibit bone fragility [7]. Beside the inhibitory effect of bisphosphonates on osteoclasts [8], recently a direct anti-tumor effect of ZA as well has been reported, through the inhibition of proliferation, angiogenesis, cell invasion and migration of cancer cells [9].

ZA is a specific inhibitor of farnesyl pyrophosphate (FPP) synthase, an enzyme involved in the mevalonate pathway, which produces isoprenoids and cholesterol [10]. Isoprenoid compounds, such as FPP and/or geranylgeranyl pyrophosphate are required for post-translation prenylation of several regulatory proteins. Among them are the small 
GTPases of the Ras and Rho family, which are farnesylated and geranylgeranylated, respectively [11-13]. Both members of the Ras and Rho family have been reported to be involved in tumorigenesis and metastasis $[14,15]$. Therefore, the hypothesis we want to test in the current study is that the antiinvasive properties of ZA may be due in part to the inhibition of RhoA activation, a key player in the organization of actin cytoskeleton and cell motility [16]. In our laboratory, we have already demonstrated a strict involvement of RhoA activation in prostate cancer cell motility. Indeed PC3 cells, following Ephrin Receptor A2 (EphA2) activation, elicit a repulsive response that is fulfilled through a Rho-dependent actino/myosin contractility activation, leading to cell body retraction [17]. RhoA activation is involved in amoeboid motility, hence allowing trans-endothelial migration and metastatic colonization of PC3 cells $[18,19]$. An impairment of RhoA activation, due to EphA2 silencing, strongly decreases the tumorigenic potential of PC3 cells [20].

Recently, our group has also shown that ZA is able to impair both M2 macrophage polarization and cancerassociated fibroblast (CAF) activation, thus affecting the microenvironment of tumor cells [21]. The aim of our work was to investigate the possible direct effect of ZA administration on the invasive properties of PC3 cells, characterised by Rho-dependent amoeboid motility.

\section{MATERIALS AND METHODS}

\subsection{Materials}

Unless specified, all reagents were obtained from Sigma (St. Louis, MO, USA) and all the antibodies were from Santa Cruz Biotechnology (Santa Cruz, CA, USA) except for antiphospho MLC (Ser 19) (Cell Signalling, Danvers, MA, USA). Matrigel Matrix was purchased from BD Biosciences (San Jose, CA, USA). ZOMETA (Zoledronic acid) was from Novartis (Basel, Switzerland). The invasion chambers were from Corning Costar (NY, USA). Ilomastat was from Chemicon International (Temecula, CA, USA). Type I collagen was from RD Systems (Minneapolis, MN, USA). Fluorescein isothiocyanate (FITC)-Phalloidin was from Molecular Probes (Eugene, OR, USA). Secondary antibodies conjugated with Alexa Fluor 488 and CellTraceTM Carboxyfluorescein succinimidyl ester (CFSE) were from Life Technologies Invitrogen (Carlsbad, CA, USA). CellTracker ${ }^{\mathrm{TM}}$ Orange (5-(and-6)-((4-chloromethyl)benzoyl)amino) tetramethylrhodamine) (CMTMR) Dye was from Thermo Fisher Scientific (Waltham, MA, USA). Glutathione S-transferase (GST)-Rhotekin was from Peprotech (London, UK) .

\subsection{Cell Cultures}

The PC3 human prostate cancer cell line derived from bone metastasis of a grade IV prostatic adenocarcinoma and human umbilical vein endothelial cells (HUVECs) were purchased from the European Collection of Cell Cultures (ECACC, Salisbury, UK). PC3 docetaxel resistant cells (PC3-DR) were obtained from our laboratory as previously described [22]. CAFs were isolated from surgical explant after patients' informed consent as previously described [23]. PC3 cells and CAFs were cultured in DMEM containing $10 \%$ Foetal Bovine Serum (FBS). HUVECs were cultured as previously reported [24]. Preparation of conditioned medium
(CM): $\mathrm{CM}$ was obtained from CAFs grown to sub-confluence and then maintained in serum-free medium for $48 \mathrm{~h}$.

\subsection{Western Blot Analysis}

Cells were lysed in Radioimmunoprecipitation Assay (RIPA) buffer and 20-50 $\mu$ g of total proteins were loaded on precast SDS-PAGE gels (BioRad, Hercules, CA, USA). Western blot analysis was performed as previously described [25].

\subsection{RhoA Activity Assay}

Cells were directly lysed in RIPA buffer, the lysates were clarified by centrifugation and RhoA-GTP was quantified as previously described [20].

\subsection{Cell Fractionation}

To detect the isoprenylated/active membrane-associated RhoA protein and the non-isoprenylated cytosolic form, cells were lysed with magnesium-containing lysis buffer (MLB) buffer $(125 \mathrm{mmol} / \mathrm{L}$ Tris- $\mathrm{HCl}, 750 \mathrm{mmol} / 1 \mathrm{NaCl}, 1 \% \mathrm{v} / \mathrm{v}$ NP40, $10 \% \mathrm{v} / \mathrm{v}$ glycerol, $50 \mathrm{mmol} / \mathrm{L} \mathrm{MgCl} 2,5 \mathrm{mmol} / \mathrm{L}$ EDTA, $25 \mathrm{mmol} / \mathrm{L}$ NaF, 1mmol/L NaVO4, $10 \mu \mathrm{g} / \mathrm{ml}$ leupeptina, $10 \mu \mathrm{g} / \mathrm{ml}$ pepstatin, $10 \mu \mathrm{g} / \mathrm{ml}$ aproteinin, $1 \mathrm{mmol} /$ L phenyl-methylsulfonyl fluoride, $\mathrm{pH}$ 7.5) and centrifuged at $13000 \mathrm{xg}$ for $10^{\prime}$ at $4^{\circ} \mathrm{C}$ according to Riganti et al. [26].

\subsection{Invasion Assay}

Cells were serum starved and treated or not with $25 \mu \mathrm{M}$ $\mathrm{ZA}$ for $48 \mathrm{~h}$ and then $8 \times 10^{4}$ cells were seeded onto Matrigel-precoated Boyden chamber $(8 \mathrm{~mm}$ pore size, $6.5 \mathrm{~mm}$ diameter, $12.5 \mu \mathrm{g}$ Matrigel/filter) with or without $50 \mu \mathrm{M}$ Ilomastat. In the lower chamber, complete medium was added as chemoattractant. Invaded cells were quantified as previously reported [21].

\subsection{Gelatin Zymography}

Serum-free medium from a monolayer of cells was collected and $20 \mu \mathrm{l}$ were added to sample buffer (SDS $0.4 \%$, 2\% glycerol, $10 \mathrm{mM}$ Tris- $\mathrm{HCl}, \mathrm{pH}$ 6.8, 0.001\% bromphenol blue). The sample were run and then incubated as previously reported [27].

\subsection{Cell Adhesion to Endothelium}

Adhesion to endothelium was performed as previously described [28]. Briefly, $6 \times 10^{4}$ CSFE (360 ng/mL) labelled PC3 cells were directly seeded for $2 \mathrm{~h}$ onto a monolayer of HUVEC cells. The adherent cells were fixed in methanol, photographed using an inverted fluorescent microscope and then quantified by counting the CSFE-positive cells.

\subsection{Trans-endothelial Cell Migration}

HUVECs were grown to confluence on the separating filter of a Transwell and activated for 90' with $10 \mathrm{ng} / \mathrm{ml} \mathrm{TNF} \alpha$. $8 \times 10^{4}$ CSFE $(360 \mathrm{ng} / \mathrm{ml})$ labelled PC3 were seeded onto HUVEC cells monolayer. Trans-endothelial cell migration was performed as previously described [18]. Complete me- 
dium was added as chemoattractant. Following $16 \mathrm{~h}$, noninvading cells on the upper surface were removed with a cotton swab. Migrated cells were photographed using an inverted fluorescent microscope and then quantified by counting the CSFE-positive cells.

\subsection{Cell Migration in Three-dimensional Collagen Ma- trices}

Reconstruction by time-lapse video microscopy and confocal microscopy was performed on PC3 cells treated or not with $25 \mu \mathrm{M}$ ZA for $48 \mathrm{~h}$. Cells were detached by EDTA ( 2 $\mathrm{mM}$ ), washed, incorporated into three-dimensional collagen lattice $(1.67 \mathrm{mg} / \mathrm{mL}$; native dermal bovine type I collagen) and monitored by time-lapse video microscopy . Cells within the lattice were labelled by CFSE $(360 \mathrm{ng} / \mathrm{mL})$, and monitored as previously described [24].

\subsection{Immunofluorescence}

Confocal analysis was performed as previously reported [24]. Briefly, PC3 cells were fixed in p-formaldehyde $(4 \%$ $\mathrm{v} / \mathrm{v}$ in PBS) for 20', permeabilized in Triton X-100 $(0.5 \%$ $\mathrm{v} / \mathrm{v}$ in PBS) for 5', then washed twice with bovine serum albumin (BSA) $(1 \% \mathrm{v} / \mathrm{v})$ and FBS $(5 \% \mathrm{v} / \mathrm{v}$ in PBS) solution and incubated overnight at $4{ }^{\circ} \mathrm{C}$ with primary antibodies against phospho-MLC (1:100). After two washes with PBS, the cells were incubated with anti-rabbit AlexaFluor 488 antibodies (1:1000). Incubation with FITC-Phalloidin was performed for $1 \mathrm{~h}$ at room temperature in the dark. The coverslips were mounted in Gel Mount ${ }^{\mathrm{TM}}$ Aqueous Mounting Medium (Sigma-Aldrich, St. Louis, MO, USA). A Nikon Eclipse TE2000-U (Nikon, Tokio, Japan) confocal microscope was used for data acquisition.

\subsection{In vivo Experiments}

In vivo experiments were performed in accordance with national guidelines and approved by the ethical committee of Animal Welfare Office of Italian Work Ministry and conformed to the legal mandates and Italian guidelines for the care and maintenance of laboratory animals. Lung retention assay. $0.5 \times 10^{6}$ cells, treated or not with $25 \mu \mathrm{M} \mathrm{ZA}$ for $48 \mathrm{~h}$ in serum-free medium, were labelled with CellTracker ${ }^{\mathrm{TM}}$ Orange CMTMR Dye and injected into the tail vein of 6- to 8-week-old male SCID bg/bg mice (Charles River Laboratories International, Wilmington, MA, USA). Mice were sacrificed at $24 \mathrm{~h}$ and lung fixed for $24 \mathrm{~h}$ in $4 \% \mathrm{p}$-formaldehyde. Lungs were then analysed under the inverted Leica SP5 confocal microscope (Leica, Wetzlar, Germania) (and 10 randomly chosen fields taken across the whole lung as previously reported [29]. Lung colonization assay. $0.5 \times 10^{6} \mathrm{PC} 3$ cells or PC3 cells treated with $25 \mu \mathrm{M} \mathrm{ZA}$ for $48 \mathrm{~h}$ in serum-free medium were injected into the tail vein of SCID bg/bg mice. 6 Male SCID-bg/bg mice (6 to 8 weeks old) per group were used. Mice were assessed weekly for weight (weight of mice at the beginning of treatment: mean $19,8 \mathrm{gr}$ ). ZA 100 $\mu \mathrm{g} / \mathrm{kg} /$ mouse was administered intraperitoneally once a week. Mice were sacrificed after 8 weeks and the lungs were inspected for metastatic nodules by histological analyses as previously reported [18]. The bar graph reports the number of metastatic nodules and paraffin-embedded tissue sections from lung metastases stained with Hematoxylin and Eosin stain (H\&E) are shown.

\subsection{Histopathological Sample Preparation}

Excised lungs were fixed overnight in $4 \%$ pformaldehyde for $24 \mathrm{~h}$, washed in PBS and embedded in paraffin for H\&E staining: $4 \mu \mathrm{m}$ tissues sections were stained with Hematoxylin (Polyscience, Inc Warrington, PA) for 40" and with Eosin (Sigma, St. Louis, MO, USA) for 30". Tissues sections were examined under a light microscope Leica DM3000 (Leica, Wetzlar, Germania).

\subsection{Statistical Analysis}

Data are presented as means \pm SD from at least three independent experiments with three independent technical replicates. Statistical analysis of the data was performed with Microsoft Office Excel 2016 (Microsoft Corporation, Redmond, WA, USA) using two tails homoscedastic Student's t test. $P$ values of $\leq 0.05$ were considered statistically significant.

\section{RESULTS}

\subsection{ZA Inhibits Invasion of PC3 Cells and RhoA Activity}

We have previously reported that PC 3 cells invasion is characterised by amoeboid motility, a process that is dependent on the activation of the small GTPase RhoA [17, 19]. Our aim was to investigate whether ZA administration could have a role in controlling both in vitro cell invasion and RhoA activity. The PC3 amoeboid motility style is shown by live imaging of cells in three-dimensional collagen lattice. Untreated PC3 cells, when exposed to three-dimensional matrices of type I collagen, move through a round-shape squeezing movement, independent of matrix degradation, forming blebs, proving a typical amoeboid motility. Conversely, ZA treatment strongly prevents PC3 movement (Fig. $\mathbf{1 A}$ and movies 1-2). Impairment of ZA-treated PC3 cells was confirmed by a statistically significant decrease in cell invasion (Student t-test, $* \mathrm{p}<0.001 \mathrm{ZA}$ treated $v s$ PC3) as well as in RhoA activation (Fig. 1B-C). We excluded a toxic effect of the drug through a dose-dependence cell-survival curve (data not shown). ZA is a specific inhibitor of farnesyl pyrophosphate (FPP) synthase in the mevalonate pathway, which produces isoprenoids and cholesterol [10]. Isoprenoids are required for post-translation prenylation of several regulatory proteins, and also for the geranyl-geranylation of RhoA [30]. Through a cell fractionation analysis, we demonstrated that ZA treatment deeply decreases the level of the prenylated, membrane bound pool of RhoA, consistent with the inhibition of its activity (Fig. 1D). Finally, we analysed the cellular localization of the phospho-myosin light chain protein (P-MLC), a known substrate of RhoA/Rhoassociated protein kinase (ROCK) signalling as well as the cytoskeleton organization by means of Phalloidin immunostaining. As shown by confocal images, ZA strongly inhibits the cortical distribution of P-MLC and causes actin depolarization with loss of the cortical ring, suggesting an impairment of RhoA dependent amoeboid motility (Fig. 1EF). 
A
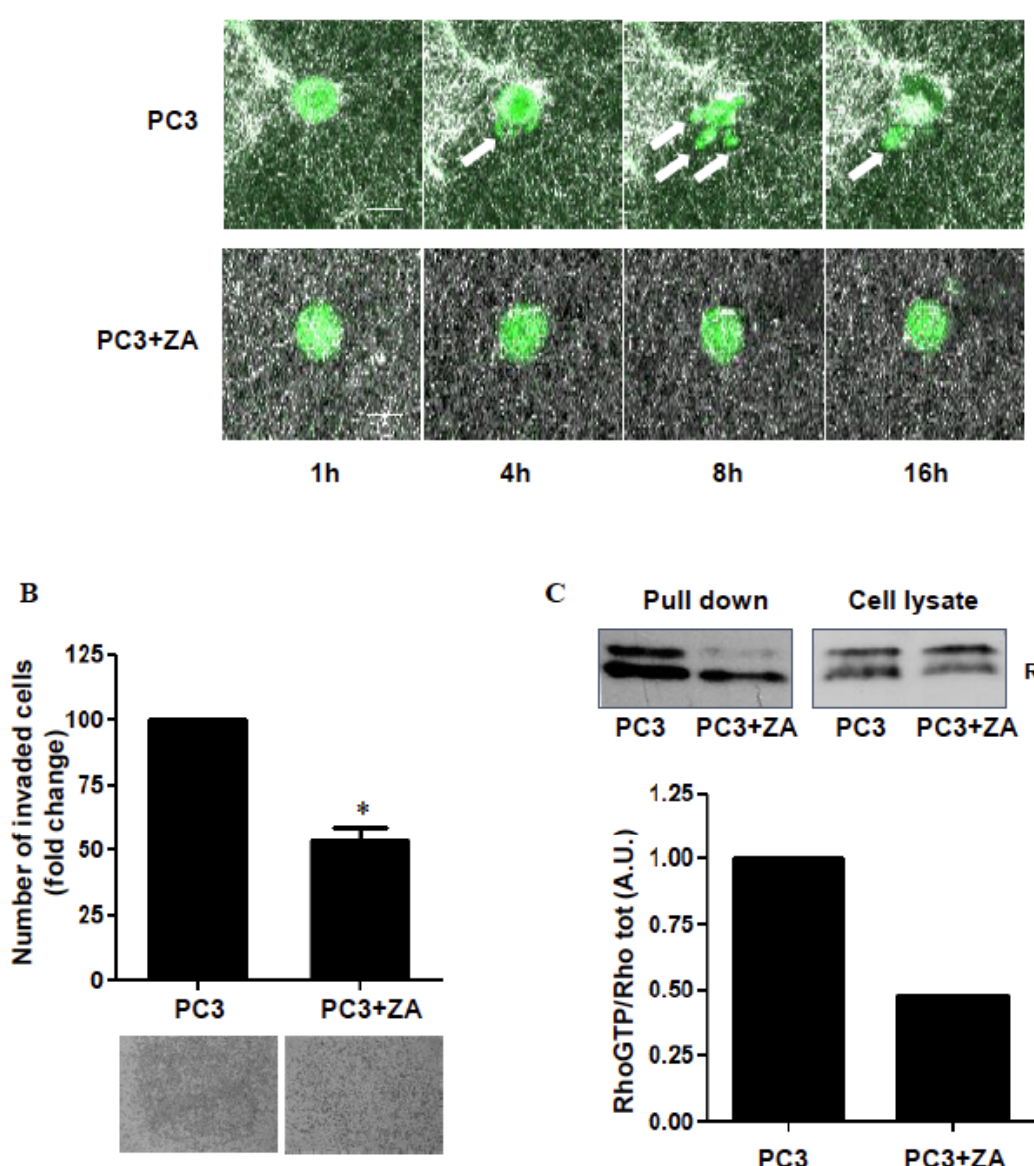

C
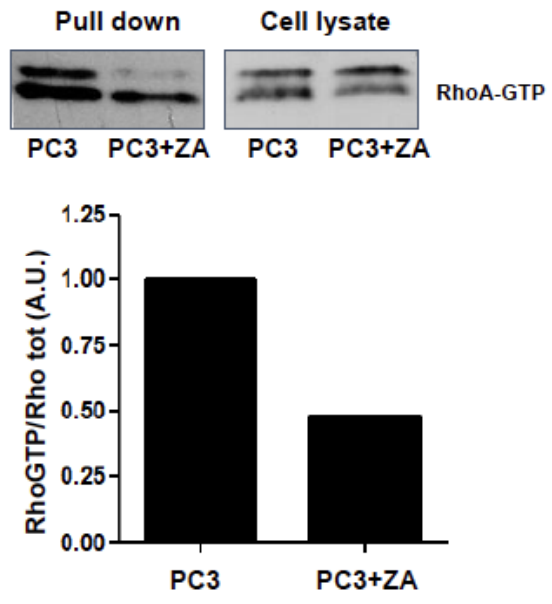

$\mathbf{E}$

D
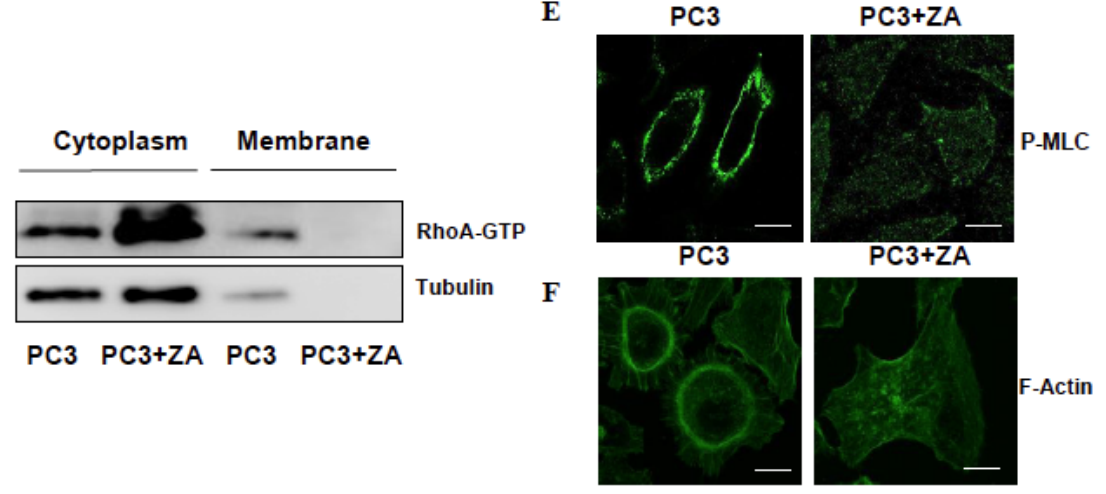

Fig. (1). ZA decreases PC3 cell invasion and RhoA activation: A) Live imaging of PC3 cells migration in three-dimensional collagen lattice. CFSE-loaded PC3 cells, treated or not with $25 \mathrm{mM}$ for $48 \mathrm{~h}$, were incorporated into the collagen matrix and monitored by confocal fluorescence-reflection video microscopy. Tumor cells are visualized in green, while the back scatter signal of the collagen I is reported in white. Arrows indicate the round-shape of the cells squeezing across collagen I fibers. Scale bar: $10 \mu \mathrm{m}$. B) Boyden cell invasion assay: cells were treated as in A) and then $8 \times 10^{4}$ cells were seeded into the upper compartment of Boyden chamber and allowed to invade through the Matrigel coated filter towards complete medium. Cell invasion was evaluated after Diff-Quick staining by counting cells in six randomly chosen fields. The results are representative of three experiments with similar results. Student t-test, * p $<0.001 \mathrm{ZA}$ treated $v s$ PC3. C) PC3 cells were treated with $25 \mu \mathrm{M}$ ZA for $48 \mathrm{~h}$ in serum free medium. After treatment, RhoA-GTP was analysed by pull-down assay from cell lysates. The total amount of RhoA was quantified by anti-RhoA immunoblot. The bar graphs obtained from densitometry analysis of the immunoblot is shown. D) Cell Fractionation: cells were treated as in A and then cytosolic and membrane fractions were isolated. Anti-RhoA and tubulin immunoblots were performed on total cell lysates, cytoplasmic and membrane fractions. E) Confocal microscopy images of antiphospho-MLC immunohistochemistry of PC3 cells treated as in A. Scale bar: $5 \mu \mathrm{m}$. F) Representative confocal microscopy images of F-actin (FITC-Phalloidin) staining of PC3 cells treated as in A) Scale bar: $5 \mu \mathrm{m}$. The images are representative of three independent experiments with similar results. 
A

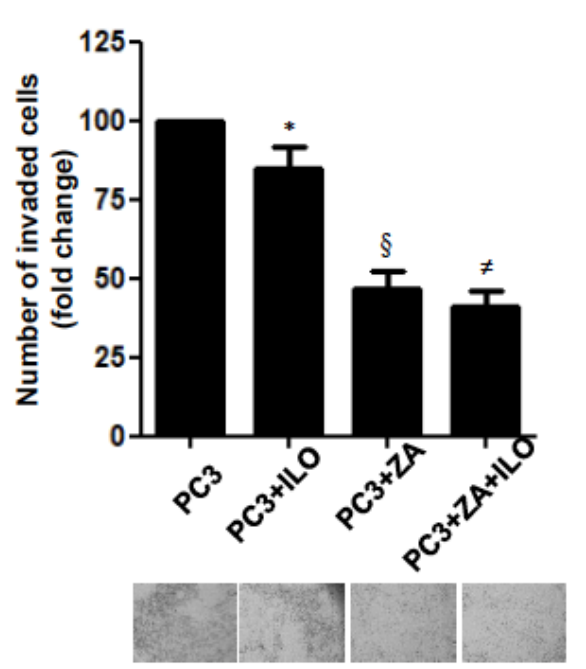

C

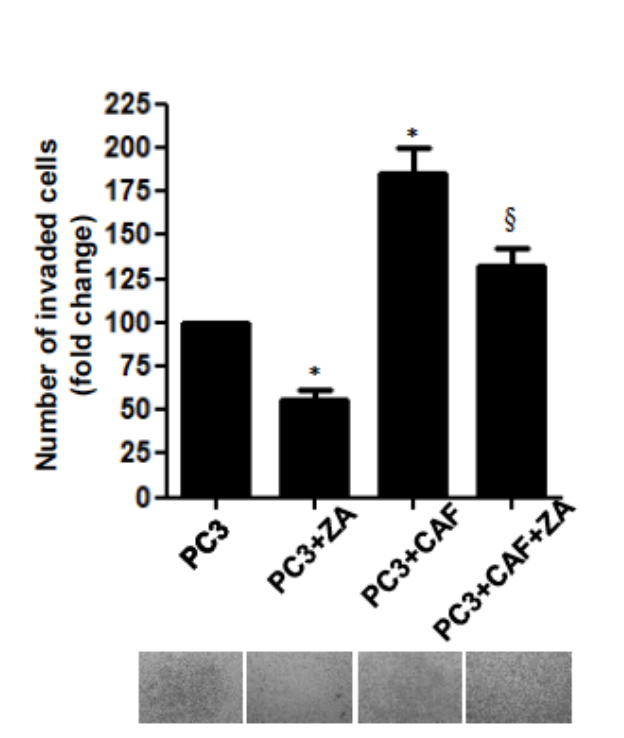

B

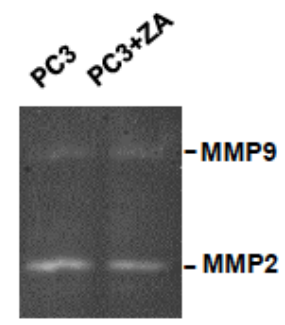

D



Fig. (2). ZA inhibits specifically amoeboid motility of PC3 cells: A) Boyden cell invasion assay. PC3 cells were treated or not with $25 \mu \mathrm{M}$ $\mathrm{ZA}$ for $48 \mathrm{~h}$ in serum-free medium and then $8 \times 10^{4}$ cells were seeded into the upper compartment of Boyden chamber with or without the MMPs inhibitor Ilomastat $50 \mu \mathrm{mol} / \mathrm{L}$. Cells were allowed to migrate through the filter coated with Matrigel toward the lower compartment filled with complete medium. Cell invasion was evaluated after Diff-Quick staining by counting cells in 6 randomly chosen fields. Student ttest, $* \mathrm{p}<0.05$ vs PC3; $(; \neq \mathrm{p}<0.001 \mathrm{ZA}+$ Ilomastat $v s$ Ilomastat B) Analysis of MMP activity. Media from a confluent monolayer of cells treated or not with $25 \mu \mathrm{M}$ ZA for $48 \mathrm{~h}$ in serum-free medium were collected and analysed by gelatin zymography. The clear bands represent areas of gelatinase activity. The results shown are representative of three experiments. C) PC3 cells were treated or not with CAF-conditioned medium (CM) for $72 \mathrm{~h}$ to induce the EMT. Then cells were treated as in A) and a Boyden cell invasion assay was performed. Student t-test, * $\mathrm{p}<0.001$ vs PC3; $\S \mathrm{p}<0.01$ CAF+ZA vs CAF D) PC3 cells or mesenchymal PC3-DR cells were treated as in A and Boyden cell invasion assays were performed. Student t-test, * $\mathrm{p}<0.001 v s \mathrm{PC} 3 ; \S \mathrm{p}<0.01 \mathrm{DR}+\mathrm{ZA} v s \mathrm{DR}$.

\subsection{ZA Inhibits Specifically Amoeboid Motility of PC3 Cells}

To verify the hypothesis that ZA actually affects in vitro amoeboid motility of $\mathrm{PC} 3$ cells we performed invasion assays in the presence of both ZA and Ilomastat. Ilomastat is a broad-range inhibitor of metallo-proteinases (MMPs) thus able to interfere with the motility-types of invasion that depend on extracellular matrix degradation. Results show that PC3 cells, which move by amoeboid motility, are only slightly sensitive to Ilomastat treatment $(* \mathrm{p}<0.05$ PC3+ILO vs PC3) while are efficiently blocked in their invasion by ZA administration ( $\S \mathrm{p}<0.001 \mathrm{PC} 3+\mathrm{ZA} v s$ PC3) (Fig. 2A). These data further corroborate the specificity of $\mathrm{ZA}$ in the inhibition of the amoeboid motility. Furthermore, we demonstrated that ZA does not affect MMPs activity as shown by gelatin zymography of culture media recovered from PC3 cells that have been subjected to ZA administration (Fig. 2B). Moreover, to confirm this effect, we assessed 
A
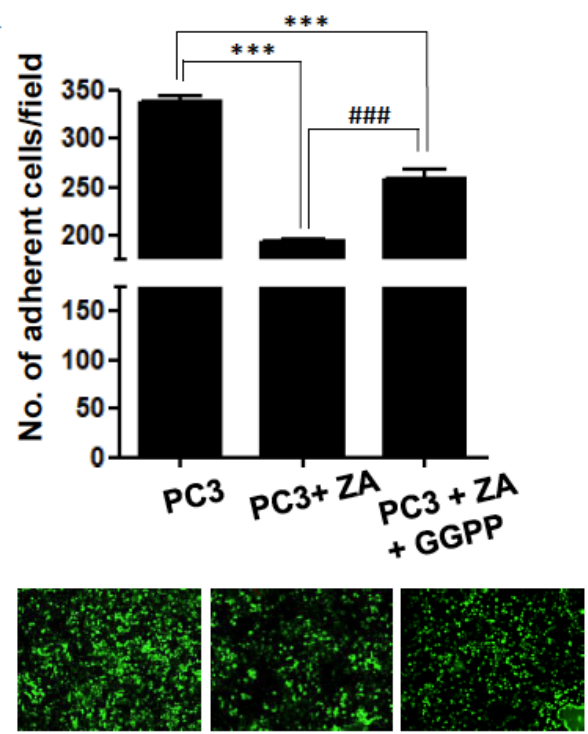

B

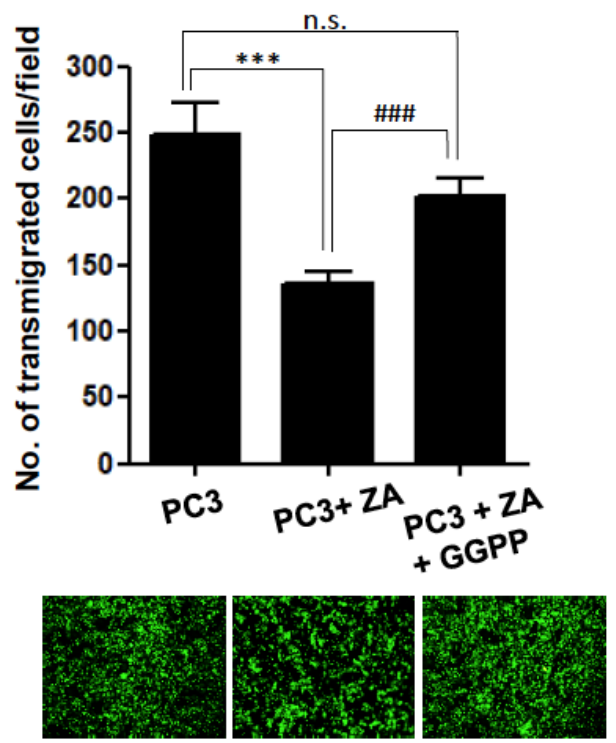

Fig. (3). ZA inhibits adhesion of PC3 and their trans-endothelial migration through the endothelium: Adhesion through endothelium: 6 x $10^{4}$ CSFE labelled PC 3 cells treated or not with $25 \mu \mathrm{M}$ ZA alone or in combination with $20 \mu \mathrm{M}$ GGPP in serum-free medium for $48 \mathrm{~h}$ were directly seeded for $2 \mathrm{~h}$ onto a monolayer of HUVEC cells. The adherent cells were photographed using an inverted fluorescent microscope and then quantified by counting the CSFE-positive cells. Results are present as mean of three biological replicates \pm SEM. Student t-test, $* * *$ $\mathrm{p}<0.001$ vs St Med; \#\#\# p $<0.001$ ZA + GGPP $v$ Z ZA. B) $8 \times 10^{4}$ CSFE labelled PC3 cells treated or not with $25 \mu \mathrm{M}$ ZA alone or in combination with $20 \mu \mathrm{M}$ GGPP in serum- free medium for $48 \mathrm{~h}$ were plated onto a monolayer of HUVECs and let trans-migrate over-night. Migrated cells were photographed using an inverted fluorescent microscope and quantified. Results are present as the mean of three biological replicates \pm SEM. Student t-test, ${ }^{* * *} \mathrm{p}<0.001$ vs St Med; \#\#\# $\mathrm{p}<0.001 \mathrm{ZA}+$ GGPP vs ZA.

the sensitivity of mesenchymal addicted PC3 cells to ZA. To this purpose we used two different models of PC3 cells that are invading with a mesenchymal-type of movement: PC3 cells treated with conditioned medium derived from CAF [25] or docetaxel resistant PC3 cells (PC3-DR), which have achieved mesenchymal features following the acquisition of drug resistance [31]. As shown, both models of PC3 invading through a mesenchymal motility, show a statistically significant lower sensitivity to the ZA treatment with respect to PC3 cells that are invading with an amoeboid type of movement, suggesting a strong action of ZA on amoeboid motility inhibition (Fig. 2C-D).

\subsection{ZA Inhibits both the Adhesion of PC3 to the Endo- thelium and Trans-endothelial Cell Migration Affecting PC3 Metastatic Dissemination}

PC3 cells possess a high plasticity in cell motility: we have previously demonstrated that amoeboid motility confers to PC3 cells the ability to effectively adhere to the endothelium and to increase their trans-endothelial migration capacity thus sustaining the metastatic process [18]. We have now tested the in vitro ability of ZA to inhibit these two phenomena that are dependent on amoeboid motility. CSFE labelled PC3 cells treated with or without ZA were allowed to adhere (Fig. 3A) or to migrate through (Fig. 3B) a monolayer of endothelial HUVEC cells. Representative pictures show that both these key phenomena involved in the metastatic process, are inhibited by ZA administration. According to the dependence of these phenomena on amoeboid motility reliant on RhoA activation, the treatment with geranyl-geranyl pyrophosphate (GGPP), which restores the prenylation of GTPase signalling proteins [21], partially restores both adhe- sion and trans-endothelial migration of PC3 cells (Fig. 3AB).

Finally, to prove whether ZA-mediated decrease in tumor-endothelial cell interaction could exert a reduction of PC3 in vivo metastatic potential, we performed a lung retention assay: PC 3 cells and ZA treated PC3 cells were labelled and injected into the tail vein of SCID bg/bg mice. As shown in Fig. (4A), ZA impairs lung retention suggesting a role in the inhibition of the metastatic process. To further corroborate this hypothesis we performed an experimental metastasis assay in SCID bg/bg mice. PC3 cells were injected into the tail vein of SCID bg/bg mice and ZA administrated intraperitoneally once a week. Lungs inspection shows that ZA treatment statistically inhibits lung colonization thus confirming a crucial role of ZA-mediated inhibition of amoeboid motility in the in vivo metastatic process of PC 3 cells.

\section{DISCUSSION}

Among the members of the bisphosphonate family, ZA has been until recently the only standard of care for the prevention of SREs in metastatic prostatic cancer, multiple myeloma and metastatic breast cancer [7, 32, 33]. ZA inhibits the FPP synthase. FPP synthase is a ubiquitously expressed enzyme in mammalian cells, nevertheless, ZA-induced apoptosis only occurs in osteoclasts. This is likely due to the high affinity of bisphosphonates to selectively adhere to the bone and being here retained, reach a high local concentration before osteoclasts-mediated endocytosis. Once within the osteoclasts, the inhibition of post-translational modification of proteins such as Rac, Rab and Rho, which have a central role in the regulation of stress fibres assembly, membrane ruffling and cell survival, leads finally to osteoclast apoptosis $[6,34]$. 
A

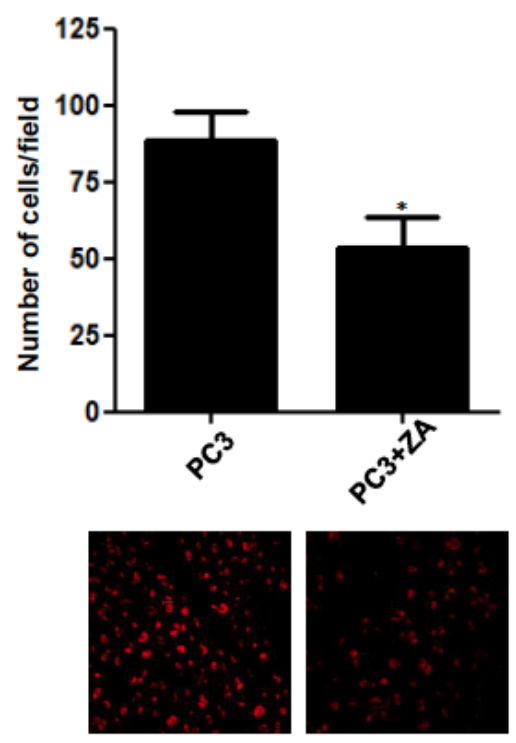

B

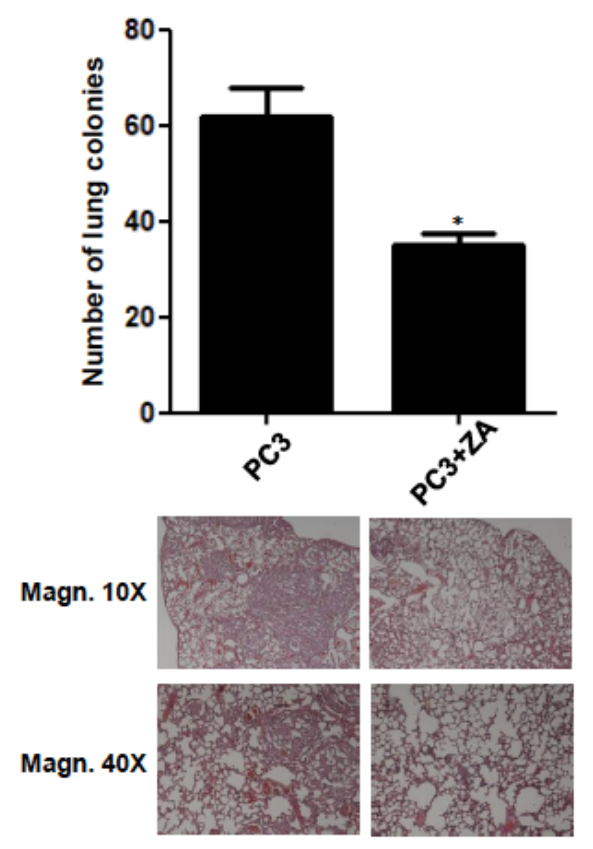

Fig. (4). ZA impairs retention and lung colonization in SCID bg/bg mice: A) Lung retention assay: $0.5 \times 10^{6}$ PC 3 cells or PC 3 cells treated with $25 \mu \mathrm{M}$ ZA for $48 \mathrm{~h}$ in serum-free medium were labelled with CellTrackerTM Orange CMTMR Dye and then injected into the tail vein of SCID bg/bg mice. After $24 \mathrm{~h}$ mice were sacrificed and the lungs examined under the inverted Zeiss microscope and 10 randomly chosen fields taken across the whole lung. Student t-test, $* \mathrm{p}<0.05 \mathrm{ZA}$ treated $v s$ PC3 B) Lung colonization assay: mice were injected into the lateral tail vein with $0.5 \times 10^{6} \mathrm{PC} 3$ cells treated as in A). ZA $100 \mu \mathrm{g} / \mathrm{kg} /$ mouse was administered intraperitoneally once a week. Mice were sacrificed after 8 weeks and the lungs were inspected for metastatic nodules by histological analyses. The bar graph reports the number of metastatic nodules and paraffin-embedded tissue sections from lung metastases stained with H\&E are shown. Student t-test, ${ }^{*} \mathrm{p}<0.005 \mathrm{ZA}$ treated $v s$ PC3.

Although ZA is not administrated to prevent tumor progression, it has been reported that it can affect several tumorrelated functions, such as angiogenesis, by inhibiting the viability of endothelial cells $[35,36]$ and immunemodulation by sustaining maturation and activation of $\gamma \delta \mathrm{T}$ cells [37-39]. Moreover, along with others, we have shown the ability of ZA to affect macrophage differentiation and fibroblast activation [1,21], both stromal cells known to play an active role in tumorigenesis and tumor progression. In addition, ZA exhibits also a direct anti-tumor activity by inhibiting cancer cells proliferation, by synergistically acting with cytotoxic agents and by decreasing cell motility $[9,40]$. A direct action of ZA in in vitro growth, migration and invasive properties of prostate cancer cells has already been described [41] but we have now further characterised the role that ZA exerts to decrease PC3-amoeboid migration which represents one of the possible invasion and motility styles of PC 3 cells. Indeed, PC3 cells possess great plasticity in cell motility and adapt their invasive strategy depending on the different extracellular stimuli. Indeed, PC3 cells can shift from mesenchymal to amoeboid motility and vice versa, adapting their motility according to the microenvironmental changes in order to optimize and finalize the metastatic process [42]. Inhibition of mesenchymal motility by administration of integrin and/or protease inhibitors, causes a clear and dramatic shift to amoeboid movements, thereby allowing cancer cells to escape pharmacological treatments [43]. Here we show that ZA inhibits in vitro RhoA activity and PC 3 cell invasion that is mainly mediated by amoeboid motility, as previously described $[17,19]$. Interestingly, ZA administration not only inhibits amoeboid motility but also prevents the shift towards mesenchymal motility, thus blocking the overall plasticity of PC3 cells. This evidence suggests that treatment with ZA may have a broad-spectrum significance thus preventing PC3 metastatic spreading.

Furthermore, ZA impedes efficiently two in vitro phenomena strictly correlated with amoeboid cell motility, namely adhesion to endothelium and trans-endothelial migration. Overall, we report that ZA impairs the metastatic potential of PC3 cells as shown by inhibition of both lung retention and lung colonization in mice. These evidences are actually remarkable since ZA is a drug able to interfere not only with the physiological function of stromal cells that compose the tumor-microenvironment (endothelial cells, macrophages, CAFs) and that are involved in cancer progression but also directly with tumor cells by decreasing their motility. Thus, differently from other pharmacological therapy, ZA could hit, at the same time, these two tumor components, inhibiting efficiently tumor progression. Indeed, it is now largely accepted that the tumor evolution depends on the active cross-talk between cancer cells and their surrounding stromal cells and both concur to successful tumor evolution [44]; thus the power of ZA is intrinsic to its dual mode of action. Furthermore, another advantage of ZA is that it could be administered not only to metastatic but also to primary cancers. Indeed, the administration of $\mathrm{ZA}$ to $\mathrm{PCa}$ patients could overcome the simple skeletal-associated side 
effect impairing directly tumor progression. The use of ZA in the treatment of SREs has been established since 2002 when a randomized trial showed that ZA reduced SRE in prostate cancer patients with bone metastases even if there was no increase in overall survival [45]. However, in accordance with our proposal, a clinical trial on early breast cancer showed a $36 \%$ decrease in disease progression in ZA arms with respect to controls, by strengthening its potential use as direct antitumor drug [46]. Indeed, the role of ZA is still ambiguous and several trials have yielded discordant results, thus further studies are needed. Nevertheless, our data suggest a possible use of this drug to directly impair tumor progression.

\section{CONCLUSION}

Our results show that ZA inhibits PC3 cells amoeboid motility and hence their invasion and trans-endothelial migration, thus suggesting ZA as a potential therapy to impede the metastatic dissemination of PC 3 cells.

\section{ABbREVIATIONS}

$$
\begin{array}{ll}
\mathrm{BSA}= & \text { Bovine serum albumin } \\
\mathrm{CAF}= & \text { Cancer associated fibroblast } \\
\text { CFSE }= & \text { Carboxyfluorescein succinimidyl ester } \\
\text { CMTMR = } & (5-(\text { and-6)-(( } 4- \\
& \text { chlorome- } \\
& \text { thyl)benzoyl)amino)tetramethylrhodamine) } \\
\text { EphA2 = } & \text { Ephrin receptor A2 } \\
\text { FITC }= & \text { Fluorescein isothiocyanate } \\
\text { FPP }= & \text { Farnesyl pyrophosphate } \\
\text { GGPP = } & \text { Geranyl-geranyl pyrophosphate } \\
\text { GST }= & \text { Glutathione S-transferase } \\
\text { MLB = } & \text { Magnesium-containing lysis buffer } \\
\text { MMPs = } & \text { Matrix metallo-proteinases } \\
\text { PCa = } & \text { Prostate cancer } \\
\text { P-MLC = } & \text { Phospho-myosin light chain } \\
\text { RIPA = } & \text { Radioimmunoprecipitation Assay } \\
\text { ROCK = } & \text { Rho-associated protein kinase } \\
\text { ZA = Zoledronic acid } &
\end{array}
$$

ETHICS APPROVAL AND CONSENT TO PARTICIPATE

Not applicable.

\section{HUMAN AND ANIMAL RIGHTS}

No Animals/Humans were used for studies that are the basis of this research.

\section{CONSENT FOR PUBLICATION}

Not applicable.

\section{CONFLICT OF INTEREST}

The authors declare no conflict of interest, financial or otherwise.

\section{ACKNOWLEDGEMENTS}

We thank Luigi Ippolito (Department of Experimental and Clinical Biomedical Sciences, University of Florence, Florence, Italy) and Andrea Morandi (Department of Experimental and Clinical Biomedical Sciences, University of Florence, Florence, Italy) for discussion and suggestions.

\section{FINANCIAL SUPPORT}

The work was supported by Associazione Italiana Ricerca sul Cancro (AIRC) (grant \#8797 to P.C.) and Istituto Toscano Tumori (grant \#0203607 to P.C.)

\section{REFERENCES}

[1] Coscia, M.; Quaglino, E.; Iezzi, M.; Curcio, C.; Pantaleoni, F.; Riganti, C.; Holen, I.; Mönkkönen, H.; Boccadoro, M.; Forni, G.; Musiani, P.; Bosia, A.; Cavallo, F.; Massaia, M., Zoledronic acid repolarizes tumour-associated macrophages and inhibits mammary carcinogenesis by targeting the mevalonate pathway. J Cell Mol Med, 2010, 14 (12), 2803-15.

[2] Saad, F., Role of bisphosphonates in non-metastatic prostate cancer. Lancet Oncol, 2014, 15 (10), 1041-2.

[3] Song, Z.; Zhang, Y., Zoledronic acid treatment in advanced nonsmall cell lung cancer patients with bone metastases. Med Oncol, 2014, 31 (4), 898.

[4] Laggner, U.; Lopez, J. S.; Perera, G.; Warbey, V. S.; SitaLumsden, A.; O'Doherty, M. J.; Hayday, A.; Harries, M.; Nestle, F. O., Regression of melanoma metastases following treatment with the n-bisphosphonate zoledronate and localised radiotherapy. Clin Immunol, 2009, 131 (3), 367-73.

[5] El-Amm, J.; Aragon-Ching, J. B., Targeting Bone Metastases in Metastatic Castration-Resistant Prostate Cancer. Clin Med Insights Oncol, 2016, 10 (Suppl 1), 11-9.

[6] Singh, T.; Kaur, V.; Kumar, M.; Kaur, P.; Murthy, R. S.; Rawal, R. $\mathrm{K}$., The critical role of bisphosphonates to target bone cancer metastasis: an overview. $J$ Drug Target, 2015, 23 (1), 1-15.

[7] Morgan, G. J.; Davies, F. E.; Gregory, W. M.; Cocks, K.; Bell, S. E.; Szubert, A. J.; Navarro-Coy, N.; Drayson, M. T.; Owen, R. G.; Feyler, S.; Ashcroft, A. J.; Ross, F.; Byrne, J.; Roddie, H.; Rudin, C.; Cook, G.; Jackson, G. H.; Child, J. A.; Group, N. C. R. I. H. O. C. S., First-line treatment with zoledronic acid as compared with clodronic acid in multiple myeloma (MRC Myeloma IX): a randomised controlled trial. Lancet, 2010, 376 (9757), 1989-99.

[8] Conte, P.; Coleman, R., Bisphosphonates in the treatment of skeletal metastases. Semin Oncol, 2004, 31 (5 Suppl 10), 59-63.

[9] Zekri, J.; Mansour, M.; Karim, S. M., The anti-tumour effects of zoledronic acid. $J$ Bone Oncol, 2014, 3 (1), 25-35.

[10] Zameer, S.; Najmi, A. K.; Vohora, D.; Akhtar, M., Bisphosphonates: Future perspective for neurological disorders. Pharmacol Rep, 2018, 70 (5), 900-907.

[11] Oades, G. M.; Senaratne, S. G.; Clarke, I. A.; Kirby, R. S.; Colston, $\mathrm{K}$. W., Nitrogen containing bisphosphonates induce apoptosis and inhibit the mevalonate pathway, impairing Ras membrane localization in prostate cancer cells. $J$ Urol, 2003, 170 (1), 246-52.

[12] McCubrey, J. A.; Steelman, L. S.; Chappell, W. H.; Abrams, S. L.; Wong, E. W.; Chang, F.; Lehmann, B.; Terrian, D. M.; Milella, M.; Tafuri, A.; Stivala, F.; Libra, M.; Basecke, J.; Evangelisti, C.; Martelli, A. M.; Franklin, R. A., Roles of the Raf/MEK/ERK pathway in cell growth, malignant transformation and drug resistance. Biochim Biophys Acta, 2007, 1773 (8), 1263-84.

[13] Denoyelle, C.; Hong, L.; Vannier, J. P.; Soria, J.; Soria, C., New insights into the actions of bisphosphonate zoledronic acid in breast cancer cells by dual RhoA-dependent and -independent effects. $\mathrm{Br}$ $J$ Cancer, 2003, 88 (10), 1631-40.

[14] Adjei, A. A., Ras signaling pathway proteins as therapeutic targets. Curr Pharm Des, 2001, 7 (16), 1581-94. 
[15] Sahai, E.; Marshall, C. J., RHO-GTPases and cancer. Nat Rev Cancer, 2002, 2 (2), 133-42.

[16] Evers, E. E.; Zondag, G. C.; Malliri, A.; Price, L. S.; ten Klooster, J. P.; van der Kammen, R. A.; Collard, J. G., Rho family proteins in cell adhesion and cell migration. Eur J Cancer, 2000, 36 (10), 1269-74.

[17] Parri, M.; Buricchi, F.; Giannoni, E.; Grimaldi, G.; Mello, T.; Raugei, G.; Ramponi, G.; Chiarugi, P., EphrinA1 activates a $\mathrm{Src} /$ focal adhesion kinase-mediated motility response leading to rho-dependent actino/myosin contractility. J Biol Chem, 2007, 282 (27), 19619-28.

[18] Giannoni, E.; Taddei, M. L.; Parri, M.; Bianchini, F.; Santosuosso, M.; Grifantini, R.; Fibbi, G.; Mazzanti, B.; Calorini, L.; Chiarugi, P., EphA2-mediated mesenchymal-amoeboid transition induced by endothelial progenitor cells enhances metastatic spread due to cancer-associated fibroblasts. J Mol Med (Berl), 2013, 91 (1), 103-15.

[19] Taddei, M. L.; Parri, M.; Angelucci, A.; Onnis, B.; Bianchini, F.; Giannoni, E.; Raugei, G.; Calorini, L.; Rucci, N.; Teti, A.; Bologna, M.; Chiarugi, P., Kinase-dependent and -independent roles of EphA2 in the regulation of prostate cancer invasion and metastasis. Am J Pathol, 2009, 174 (4), 1492-503.

[20] Taddei, M. L.; Parri, M.; Angelucci, A.; Bianchini, F.; Marconi, C.; Giannoni, E.; Raugei, G.; Bologna, M.; Calorini, L.; Chiarugi, P., EphA2 induces metastatic growth regulating amoeboid motility and clonogenic potential in prostate carcinoma cells. Mol Cancer Res, 2011, 9 (2), 149-60.

[21] Comito, G.; Pons Segura, C.; Taddei, M. L.; Lanciotti, M.; Serni, S.; Morandi, A.; Chiarugi, P.; Giannoni, E., Zoledronic acid impairs stromal reactivity by inhibiting M2-macrophages polarization and prostate cancer-associated fibroblasts. Oncotarget, 2017, 8 (1), 118-132.

[22] Ippolito, L.; Marini, A.; Cavallini, L.; Morandi, A.; Pietrovito, L.; Pintus, G.; Giannoni, E.; Schrader, T.; Puhr, M.; Chiarugi, P.; Taddei, M. L., Metabolic shift toward oxidative phosphorylation in docetaxel resistant prostate cancer cells. Oncotarget, 2016.

[23] Fiaschi, T.; Marini, A.; Giannoni, E.; Taddei, M. L.; Gandellini, P.; De Donatis, A.; Lanciotti, M.; Serni, S.; Cirri, P.; Chiarugi, P., Reciprocal metabolic reprogramming through lactate shuttle coordinately influences tumor-stroma interplay. Cancer Res, 2012, 72 (19), 5130-40.

[24] Pietrovito, L.; Leo, A.; Gori, V.; Lulli, M.; Parri, M.; Becherucci, V.; Piccini, L.; Bambi, F.; Taddei, M. L.; Chiarugi, P., Bone marrow-derived mesenchymal stem cells promote invasiveness and transendothelial migration of osteosarcoma cells via a mesenchymal to amoeboid transition. Mol Oncol, 2018, 12 (5), 659-676.

[25] Giannoni, E.; Bianchini, F.; Masieri, L.; Serni, S.; Torre, E.; Calorini, L.; Chiarugi, P., Reciprocal activation of prostate cancer cells and cancer-associated fibroblasts stimulates epithelialmesenchymal transition and cancer stemness. Cancer Res, 2010, 70 (17), 6945-56.

[26] Riganti, C.; Castella, B.; Kopecka, J.; Campia, I.; Coscia, M.; Pescarmona, G.; Bosia, A.; Ghigo, D.; Massaia, M., Zoledronic acid restores doxorubicin chemosensitivity and immunogenic cell death in multidrug-resistant human cancer cells. PLoS One, 2013, 8 (4), e60975.

[27] Comito, G.; Giannoni, E.; Segura, C. P.; Barcellos-de-Souza, P.; Raspollini, M. R.; Baroni, G.; Lanciotti, M.; Serni, S.; Chiarugi, P., Cancer-associated fibroblasts and M2-polarized macrophages synergize during prostate carcinoma progression. Oncogene, 2014, 33 (19), 2423-31.

[28] Reymond, N.; Im, J. H.; Garg, R.; Vega, F. M.; Borda d'Agua, B.; Riou, P.; Cox, S.; Valderrama, F.; Muschel, R. J.; Ridley, A. J., $\mathrm{Cdc} 42$ promotes transendothelial migration of cancer cells through $\beta 1$ integrin. J Cell Biol, 2012, 199 (4), 653-68.

[29] Taddei, M. L.; Cavallini, L.; Ramazzotti, M.; Comito, G.; Pietrovito, L.; Morandi, A.; Giannoni, E.; Raugei, G.; Chiarugi, P., Stromal-induced downregulation of miR-1247 promotes prostate cancer malignancy. J Cell Physiol, 2018.

[30] Petrylak, D. P.; Tangen, C. M.; Hussain, M. H.; Lara, P. N.; Jones, J. A.; Taplin, M. E.; Burch, P. A.; Berry, D.; Moinpour, C.; Kohli, M.; Benson, M. C.; Small, E. J.; Raghavan, D.; Crawford, E. D., Docetaxel and estramustine compared with mitoxantrone and pred- nisone for advanced refractory prostate cancer. $N$ Engl $\mathrm{J} \mathrm{Med}$, 2004, 351 (15), 1513-20.

Ippolito, L.; Marini, A.; Cavallini, L.; Morandi, A.; Pietrovito, L.; Pintus, G.; Giannoni, E.; Schrader, T.; Puhr, M.; Chiarugi, P.; Taddei, M. L., Metabolic shift toward oxidative phosphorylation in docetaxel resistant prostate cancer cells. Oncotarget, 2016, 7 (38), 61890-61904.

[32] Lipton, A.; Small, E.; Saad, F.; Gleason, D.; Gordon, D.; Smith, M.; Rosen, L.; Kowalski, M. O.; Reitsma, D.; Seaman, J., The new bisphosphonate, Zometa (zoledronic acid), decreases skeletal complications in both osteolytic and osteoblastic lesions: a comparison to pamidronate. Cancer Invest, 2002, 20 Suppl 2, 45-54.

[33] Rosen, L. S.; Gordon, D.; Kaminski, M.; Howell, A.; Belch, A.; Mackey, J.; Apffelstaedt, J.; Hussein, M.; Coleman, R. E.; Reitsma, D. J.; Seaman, J. J.; Chen, B. L.; Ambros, Y., Zoledronic acid versus pamidronate in the treatment of skeletal metastases in patients with breast cancer or osteolytic lesions of multiple myeloma: a phase III, double-blind, comparative trial. Cancer J, 2001, 7 (5), 377-87.

[34] Sackmann, E., How actin/myosin crosstalks guide the adhesion, locomotion and polarization of cells. Biochim Biophys Acta, 2015, 1853 (11 Pt B), 3132-42.

[35] Wood, J.; Bonjean, K.; Ruetz, S.; Bellahcène, A.; Devy, L.; Foidart, J. M.; Castronovo, V.; Green, J. R., Novel antiangiogenic effects of the bisphosphonate compound zoledronic acid. J Pharmacol Exp Ther, 2002, 302 (3), 1055-61.

[36] Ziebart, T.; Pabst, A.; Klein, M. O.; Kämmerer, P.; Gauss, L.; Brüllmann, D.; Al-Nawas, B.; Walter, C., Bisphosphonates: restrictions for vasculogenesis and angiogenesis: inhibition of cell function of endothelial progenitor cells and mature endothelial cells in vitro. Clin Oral Investig, 2011, 15 (1), 105-11.

[37] Dieli, F.; Gebbia, N.; Poccia, F.; Caccamo, N.; Montesano, C.; Fulfaro, F.; Arcara, C.; Valerio, M. R.; Meraviglia, S.; Di Sano, C.; Sireci, G.; Salerno, A., Induction of gammadelta T-lymphocyte effector functions by bisphosphonate zoledronic acid in cancer patients in vivo. Blood, 2003, 102 (6), 2310-1.

[38] Naoe, M.; Ogawa, Y.; Takeshita, K.; Morita, J.; Shichijo, T.; Fuji, K.; Fukagai, T.; Iwamoto, S.; Terao, S., Zoledronate stimulates gamma delta $\mathrm{T}$ cells in prostate cancer patients. Oncol Res, 2010, $18(10), 493-501$.

[39] Santini, D.; Martini, F.; Fratto, M. E.; Galluzzo, S.; Vincenzi, B.; Agrati, C.; Turchi, F.; Piacentini, P.; Rocci, L.; Manavalan, J. S.; Tonini, G.; Poccia, F., In vivo effects of zoledronic acid on peripheral gammadelta $\mathrm{T}$ lymphocytes in early breast cancer patients. Cancer Immunol Immunother, 2009, 58 (1), 31-8.

[40] Jiang, P.; Zhang, P.; Mukthavaram, R.; Nomura, N.; Pingle, S. C.; Teng, D.; Chien, S.; Guo, F.; Kesari, S., Anti-cancer effects of nitrogen-containing bisphosphonates on human cancer cells. Oncotarget, 2016, 7 (36), 57932-57942.

[41] Mani, J.; Vallo, S.; Barth, K.; Makarević, J.; Juengel, E.; Bartsch, G.; Wiesner, C.; Haferkamp, A.; Blaheta, R. A., Zoledronic acid influences growth, migration and invasive activity of prostate cancer cells in vitro. Prostate Cancer Prostatic Dis, 2012, 15 (3), 250-5.

[42] Taddei, M. L.; Giannoni, E.; Comito, G.; Chiarugi, P., Microenvironment and tumor cell plasticity: an easy way out. Cancer Lett, 2013, 341 (1), 80-96.

[43] Wolf, K.; Friedl, P., Molecular mechanisms of cancer cell invasion and plasticity. Br J Dermatol, 2006, 154 Suppl 1, 11-5.

[44] Hanahan, D.; Weinberg, R. A., Hallmarks of cancer: the next generation. Cell, 2011, 144 (5), 646-74.

[45] Saad, F.; Gleason, D. M.; Murray, R.; Tchekmedyian, S.; Venner, P.; Lacombe, L.; Chin, J. L.; Vinholes, J. J.; Goas, J. A.; Chen, B.; Group, Z. A. P. C. S., A randomized, placebo-controlled trial of zoledronic acid in patients with hormone-refractory metastatic prostate carcinoma. J Natl Cancer Inst, 2002, 94 (19), 1458-68.

[46] Gnant, M.; Mlineritsch, B.; Luschin-Ebengreuth, G.; Kainberger, F.; Kässmann, H.; Piswanger-Sölkner, J. C.; Seifert, M.; Ploner, F.; Menzel, C.; Dubsky, P.; Fitzal, F.; Bjelic-Radisic, V.; Steger, G.; Greil, R.; Marth, C.; Kubista, E.; Samonigg, H.; Wohlmuth, P.; Mittlböck, M.; Jakesz, R.; (ABCSG), A. B. a. C. C. S. G., Adjuvant endocrine therapy plus zoledronic acid in premenopausal women with early-stage breast cancer: 5-year follow-up of the ABCSG-12 bone-mineral density substudy. Lancet Oncol, 2008, 9 (9), 840-9. 